\title{
Japan opens access to mouse cDNA data...
}

\section{David Cyranoski, Tokyo}

Japanese research institutes are not known for their openness towards foreign collaborators. But a growing movement to change this was signalled by a two-week meeting in Tsukuba earlier this month, held to annotate a large set of mouse complementary DNA held by the Institute of Physical and Chemical Research (RIKEN).

Unusually for a Japanese research institute, RIKEN's Genomic Sciences Center has initiated and taken the lead in a collaboration based on the free public distribution of data and research materials.

Yoshihide Hayashizaki, a chief scientist at the centre and leader of the project, invited about 50 bioinformaticists and biologists to the Functional Annotation of Mouse (FANTOM) meeting to annotate a subset of his library of 128,500 mouse complementary DNAs, which he says is the world's largest set of mammalian cDNAs.

Many foreign participants say they were struck not only by the event's scale, but also by its taking place in Japan at all. "Japan has always been so secretive," says one US researcher. Another attributed the internationalism to Hayashizaki's efforts.

Hayashizaki says he faced a catch-22 in getting government approval for the project. "We are told to get involved in international collaborations and to make a name for Japanese science on the international scene, yet we are expected to keep results paid for by Japan- ese taxpayers, and criticized if we just give them away for other countries to profit from."

Unlike an entire genome, in which genes are interspersed with 'junk' DNA, cDNA is made from RNA produced in the cell, so each sequence represents an expressed gene.

Annotation of cDNA sequences aims to predict the structure, function, homology and protein-protein interactions of their gene products.

Huddled around computers at some times and karaoke machines at others, the group annotated about 21,000 full-length cDNAs. After removing redundant or previously known sequences, this left just under 16,000 unique cDNAs.

Researchers say they have already discovered a number of new genes, or genes that were previously unknown in mice or mammals. The similarity between the mouse and human genomes means that the mouse will almost certainly provide important clues to understanding the human genome.

The data will no doubt find profitable application. Full-length cDNA are "notoriously hard to get," says participant Peter Mombaerts, a neuroscientist at the Rockefeller University in New York, as the RNA can easily degrade during collection or form secondary structures that make it difficult to copy into cDNA.

After the results are published, Hayashizaki plans to release the data to two public databases, the DNA DataBase of Japan and

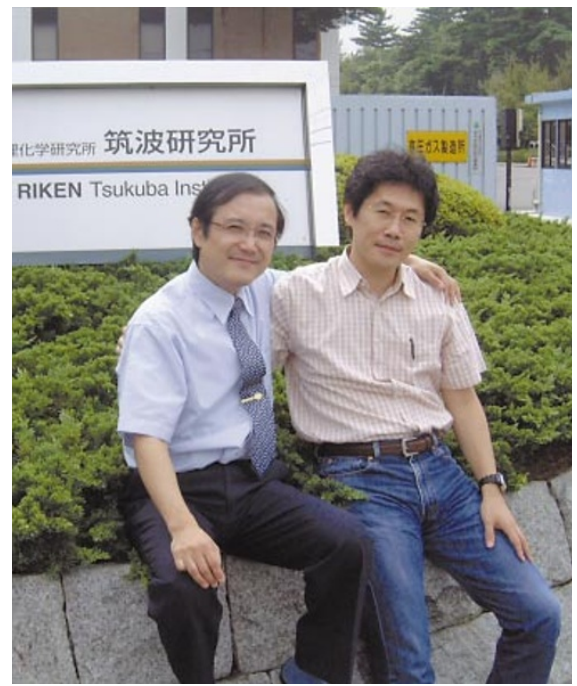

Embracing change: Hayashizaki, left, and his RIKEN colleague, Yasushi Okazaki.

the Mouse Genomic Database at the Jackson Laboratory in Bar Harbor, Maine. The cDNA clones will be made available to researchers worldwide.

Hayashizaki believes that his clones will become the standard for future research, and he is already planning FANTOM II. Many emerged from this month's meeting convinced that he has the best mouse cDNA around, and that the meeting marked a significant step for Japanese science in keeping pace with collaborative trends elsewhere.

\section{... and to report on strengths and weaknesses of genomics centre}

Anyone who wants to know what is wrong — and right — with research at the Genomic Sciences Center (GSC) of the Institute of Physical and Chemical Research (RIKEN) can turn to RIKEN's website. There they will find a detailed report containing both praise and criticism of the centre.

The material reflects the keenness of the GSC's director, Akiyoshi Wada, both to meet the Japanese public's demand for transparency in government activities and to create the openness that he feels is "necessary for interaction with the international scientific community".

In March an external advisory committee, made up of four foreign and five Japanese researchers, reviewed the GSC's five research groups. Wada, who has been GSC director for two years, has made the unconventional decision to post its

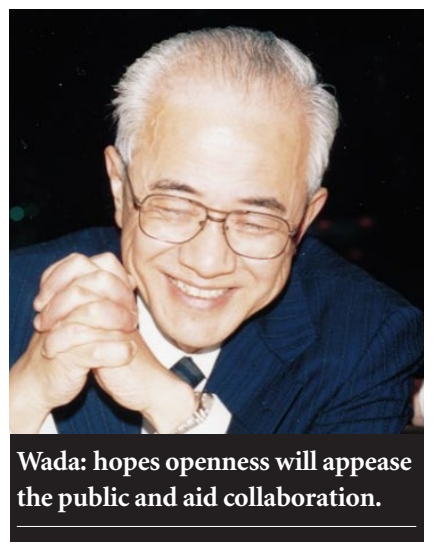

report, along with his item-by-item response, on RIKEN's website.

Panel member Kurt Wüthrich of the Institute for Molecular Biology and Biophysics at ETH-Hönggerberg in Zürich says Wada has made "a bold move". "I have served on several such committees in France and Germany, and they always make the findings 'public', but that usually just means to make public within the research institute."

The overwhelmingly positive comments - including "number one in the world" for Yoshihide Hayashizaki's project on mouse complementary DNA (see above) and "world leader, cannot be criticized" for Yoshiyuki Sakaki's Human Genome Research Group - perhaps made the decision to go public an easy one.

But Wada also had to address some delicate issues. For example, the committee suggested ways to make the GSC's new nuclear magnetic resonance facility, used for analysing protein structure, an "internationally visible, open facility".

Wada claims that it is impossible to meet these suggestions, but he is working out a compromise in which about $10 \%$ of the facility's time will go to researchers in Japan and abroad who have been selected by international committee.

Some of the research-group directors are worried that making the evaluations public could perpetuate misunderstandings. For example, Hayashizaki praised the efficiency of his "factory-like" cDNA sequencing efforts. But the report turned this description on its head, with an implication that his work is factory-like and thus not scientific.

Some government officials are worried that its international outlook prevents GSC from repaying taxpayers with 'economic fruit'. Wada replies: "There are two ways to make fruit: we could try to make money or we could raise the level of Japan's scientific reputation. The second is much greater than monetary profit." 